\title{
ДОСЛІДЖЕННЯ КОНЦЕНТРАЦІЙНИХ ЗАЛЕЖНОСТЕЙ ВОДНИХ РОЗЧИНІВ
}

\author{
П. П. Лошицький, Д. Ю. Минзяк \\ Національний технічний університет України \\ «Київський політехнічний інститут»
}

\begin{abstract}
Проведені дослідження спонтанних та індукованих вкрай високочастотним випромінюванням флуктуацій температури водних розчинів глюкози. Представлена лінійна залежність відносних величин періодів повторення автокореляційної функції та відносних частот коефріцієнтів Фур'є перетворення від концентрації водного розчину глюкози.
\end{abstract}

Ключові слова: диференціальна температура, автокореляційна функція, фолуктуація, коефіцієнти Фур'є перетворення, концентрація розчину.

\section{ИССЛЕДОВАНИЕ КОНЦЕНТРАЦИОННЫХ ЗАВИСИМОСТЕЙ ВОДНЫХ PACTBOPOB}

\author{
П. П. Лошицкий, Д. Ю. Минзяк \\ Национальный технический университет Украины \\ «Киевский политехнический институт»
}

\begin{abstract}
Проведено исследование спонтанных и индуцированных крайне высокочастотным излучением фрлукуаций температуры водных растворов глюкозы. Показана линейная зависимость относительных величин периодов повторения автокорреляционной функции и относительных частот коэффициентов Фурье преобразования от концентрации водного раствора глюкозы.
\end{abstract}

Ключевые слова: дифференциальная температура, автокорреляционная функция, флуктуация, коэффициенты Фурье преобразования, концентрация раствора.

\section{INVESTIGATION OF CONCENTRATION DEPENDENCE OF WATER SOLUTIONS}

\section{P. P. Loshytskyi, D. Yu. Mynzyak}

National Technical University of Ukraine "Kyiv Polytechnic Institute"

\begin{abstract}
This article describes a study of spontaneous and induced EHF-radiation temperature fluctuations in water solutions of glucose. There is shown a linear dependence of the relative magnitudes of repetition periods of the autocorrelation function and the relative frequencies of the Fourier transformation coefficients of the glucose concentration.
\end{abstract}

Key words: differential temperature autocorrelation function, fluctuation, the Fourier coefficients, the concentration of the solution.

Вступ. У функціонуванні і в самій можливості існування живих об' єктів вирішальну роль відіграють різні біологічні водні розчини. Різноманітні комбінації складу та концентрації цих розчинів мають широкий діапазон різних можливих варіантів. Причому, функціонування живого організму визначає основні параметри таких розчинів: склад, концентрацію, швидкості проходження біохімічних реакцій. Тому вивчення властивостей певних розчинів, пов'язаних з роботою живого організму, дає можливість діагностувати стан цього організму.
Існує актуальна необхідність розроблення методів неінвазивного безперервного моніторингу стану організму, одним із завдань якого є дослідження концентрації біологічних розчинів. На даний час для вимірювання концентрацій речовин у водних розчинах, у тому числі біологічних, у залежності від конкретних умов і вимог, розроблені та використовуються різні засоби вимірювань і прилади, що їх здійснюють. Серед них виділяють: електрохімічні способи вимірювання концентрацій [1]; спектрометричні методи вимірювань концентрацій [2]; теплові ме-

(C) П. П. Лошицький, Д. Ю. Минзяк, 2011 
тоди, а також хроматографічні методи (хроматограф) [3].

Проте, переважна частина відомих методів не може бути використана або пристосована для неінвазивного аналізу біологічних розчинів, за неможливістю реалізації безпосередньої взаємодії вимірюваного розчину та вимірювальної апаратури. Саме тому необхідна розробка і дослідження такого методу вимірювання концентрації біологічних розчинів, що може бути пристосований для неінвазивної діагностики організму. Подібний метод може використовувати параметри для визначення концентрації, що індукуються організмом у проміжне середовище між апаратурою і цим організмом.

Метою цієї роботи є розроблення та дослідження методу визначення концентрації на модельній системі розчинів глюкози.

Основна частина. Відповідно до поглядів, вперше введених у фізику Я. І. Френкелем, тепловий рух атомів або молекул рідини вдалині від критичної точки складається 3 нерегулярних коливань середньою частотою $1 /$ то, близькою до частот коливань атомів у кристалічних тілах, і амплітудою, що визначається розмірами «вільного обсягу», наданої частинці іiі сусідами. Центр коливань визначається полем сусідніх частинок і зміщується разом зі зміщеннями цих частинок. Тому, на відміну від кристала, в рідині є тільки тимчасові і нестійкі положення рівноваги. Існує такий середній час т, причому т >> то, впродовж якого центр коливань кожної частинки зміщується на величину міжатомних відстаней. Це $є$, певно, характерний час, пов'язаний з самодифузією або перемішуванням частинок рідини. Зі специфічним механізмом теплового руху частинок в рідині пов'язано ще одне цікаве фізичне явище - характерний спектр розсіяного рідиною світла. Коливальна частина теплового руху частинок в рідині може бути, як і в кристалі, зведена до набору дебаївських хвиль, які пронизують систему. У рідині колективні коливання всієї системи у вигляді дебаївських хвиль описують лише коливальну частину теплового руху частинок (майже всю), але зовсім не враховують настільки ж істотний трансляційний рух частинок. Відповідно до цього, спектр колективних коливань в рідині обривається на більш довгих, ніж у кристалів, хвилях. Залишається неупорядкована частина руху частинок, пов'язана, головним чином, з тепловим трансляційним рухом, що проявляється у вигляді порушень порядку в рідині. У термодинамічній теорії розсіювання світла ця незміщена компонента трактується як результат розсіювання світла на флуктуаціях ентропії
[4]. Наявність подібного руху в рідинах дозволяє очікувати наявності флуктуацій температури в будьякому досить малому об'ємі рідини. Причому ці флуктуації залежатимуть, в тому числі, і від дуже слабких зовнішніх впливів високої частоти. Тому в цій роботі використовується вкрай висока частота впливу низької інтенсивності, реакція рідини на яку буде залежати від концентрації розчину.

Матеріали та методи досліджень. Для досліджень використовувалася дистильована вода напівпровідникової чистоти $(99,9 \%)$ і реактиви з хімічною чистотою не менше 99\%. Розчини необхідної концентрації готувалися шляхом розчинення заданої кількості реактивів у фіксованому обсязі дистильованої води. В якості джерела зовнішнього впливу використовувався широкосмуговий генератор електромагнітних шумів, що працює в безперервному режимі в діапазоні 57...68 ГГц з рівнем спектральної щільності потужності шуму 10-18 Вт / Гц. Шумовий сигнал модулювався по амплітуді 3 випадковою частотою в діапазоні 6 ... 18 Гц. Інтегральна потужність сигналу не перевищувала рівня 10-9 Вт/см². Критерієм стану розчину і впливу на нього зовнішнього фізичного чинника була флуктуація диференціальної температури, яка вимірюється спеціально розробленим апаратурним комплексом, що забезпечує точність відносних вимірювань $0,03{ }^{0} \mathrm{C}$. Характеристики і детальна методика вимірювань апаратурного комплексу наведені у роботі [5]. За результатами вимірювань флуктуацій температури, вимірюваної протягом 25 хвилин до впливу зовнішнього фізичного чинника, протягом 25 хвилин при дії зовнішнього чинника i протягом 25 хвилин після впливу зовнішнього фізичного чинника, визначалися значення величин функції автокореляції і коефіцієнтів перетворення Фур'є дисперсії диференціальної температури кожного з випадкових процесів. Результати оброблялися за стандартною методикою в пакеті прикладних програм середовища MatLab.

Результати та обговорення. Враховуючи, що вимірювальний комплекс проводить близько 40 вимірювань в секунду, кількості вимірів протягом часу досить для оперування середніми величинами, тобто вибірки є репрезентативними. На першому етапі досліджень визначалися залежності характеристик випадкових процесів, що описують флуктуації температури, для різних концентрацій розчинів глюкози, до впливу зовнішнім чинником, під час впливу і після впливу. На рисунку 1, в якості ілюстрації, наведені залежності значень дисперсії для водних розчинів глюкози концентрацій 5 \% і 25 \% до, після і під час 

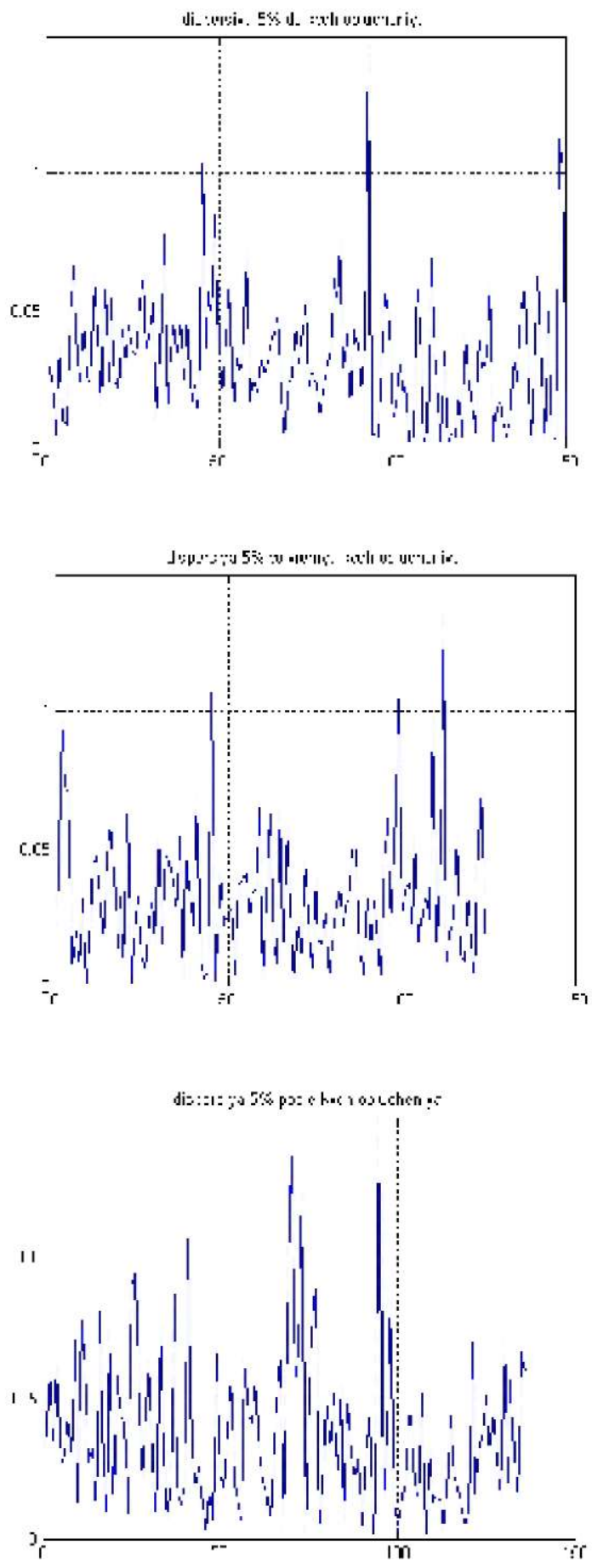

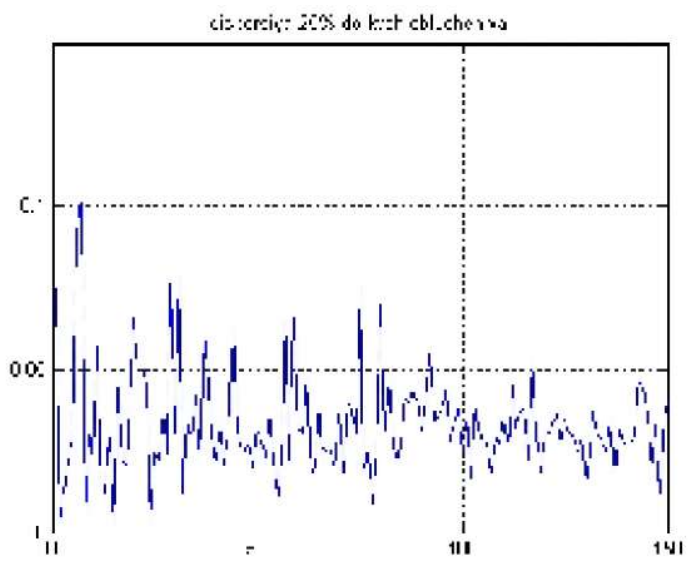

a

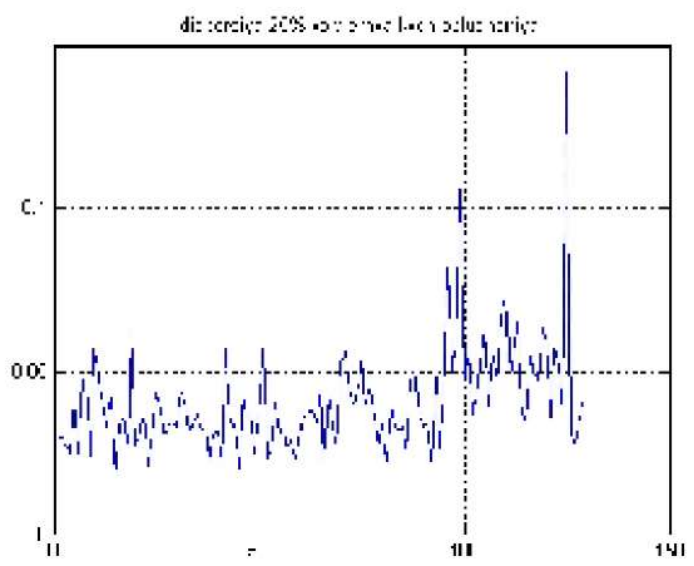

6

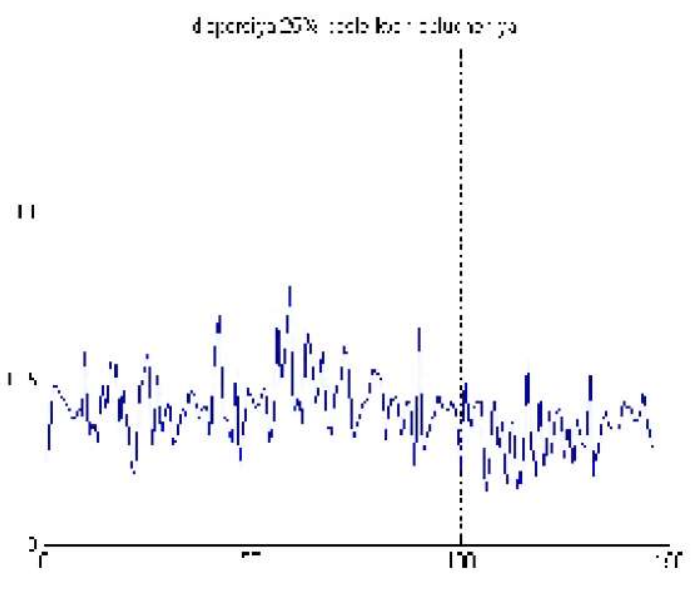

Puc. 1. Дисперсія розчинів глюкози різних концентрацій: а) до впливу ВВЧ-випромінювання; б) під час впливу ВВЧ-випромінювання; в) після впливу ВВЧ-випромінювання.

впливу широкосмуговим шумовим сигналом вкрай високих частот (ВВЧ) низької інтенсивності. Якісно помітні відмінності дисперсії при різних концентраціях. Дисперсія розчину більшої концентрації має меншу амплітуду розмаху змін, а також значно менше високочастотних компонент. Проте видимі якісні відмінності складно відобразити будь-якою кількісною залежністю. На рисунку 2 представлені функції автокореляції для тих же розчинів. Перш за все, звертає на себе увагу те, що функція автокореляції не спадає до нуля, а навпаки, величина ii збільшується, що характерно для всіх водних розчинів. Пов'язано це явище зі збільшенням впорядкованості структури водного розчину з перебігом 

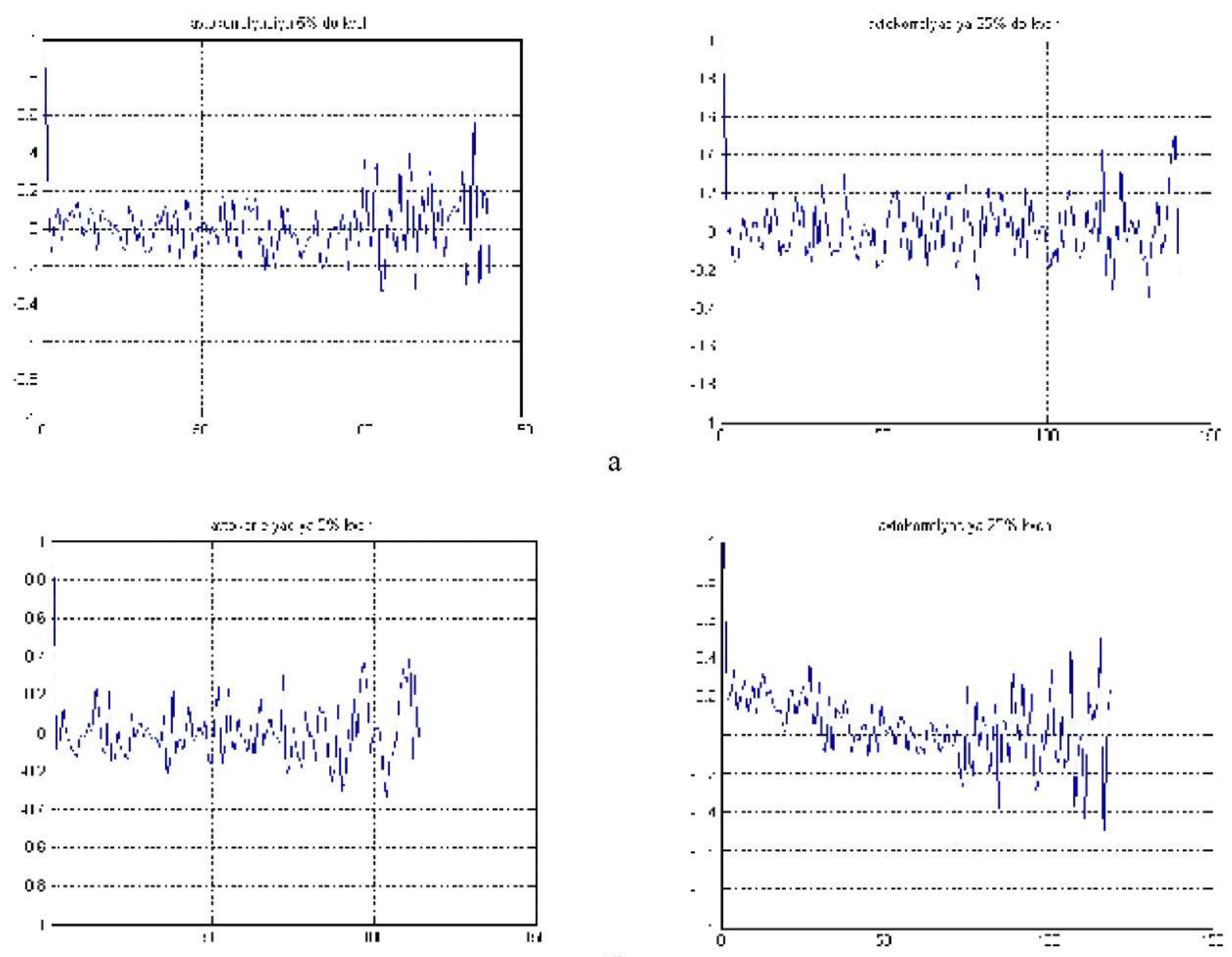

6
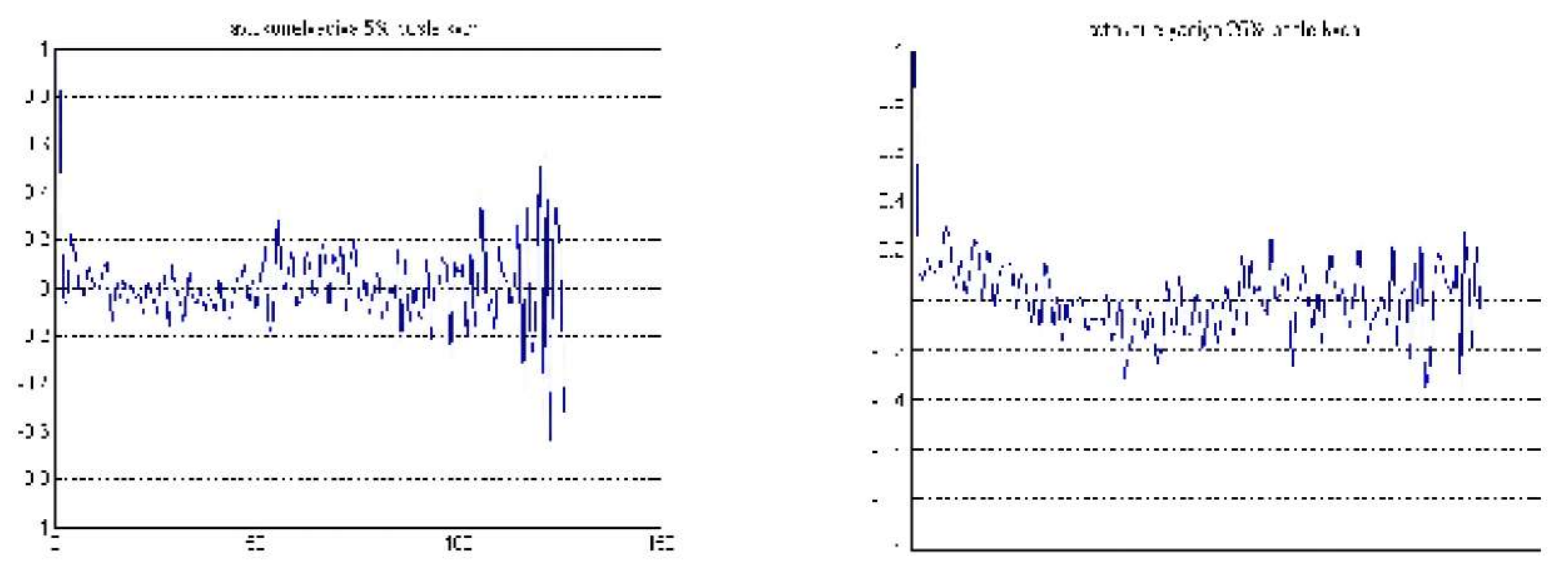

B

Puc. 2. Автокореляційна функція розчинів глюкози різних концентрацій: а) до впливу ВВЧ-випромінювання; б) під час впливу ВВЧ-випромінювання; в) після впливу ВВЧ-випромінювання.

часу, причому слабкий зовнішній вплив не руйнує, а зміцнює і прискорює структурування. При більш високій концентрації розчину краще виражені низькочастотні компоненти, особливо при дії ВВЧ - випромінювання і після нього. Якісно досить добре помітні відмінності, пов'язані зі зміною концентрації розчину. На рисунку 3 показані залежності коефіцієнтів Фур'є перетворення від відносної частоти для розглянутих водних розчинів. Якщо не акцентувати увагу на значення амплітуд коефіцієнтів Фур'є, та проаналізувати положення піків (положення відносних частот), то спостерігається певна закономірність їх розташування, яка також простежується для відносних величин періодів повторення автокореляційної функції. 

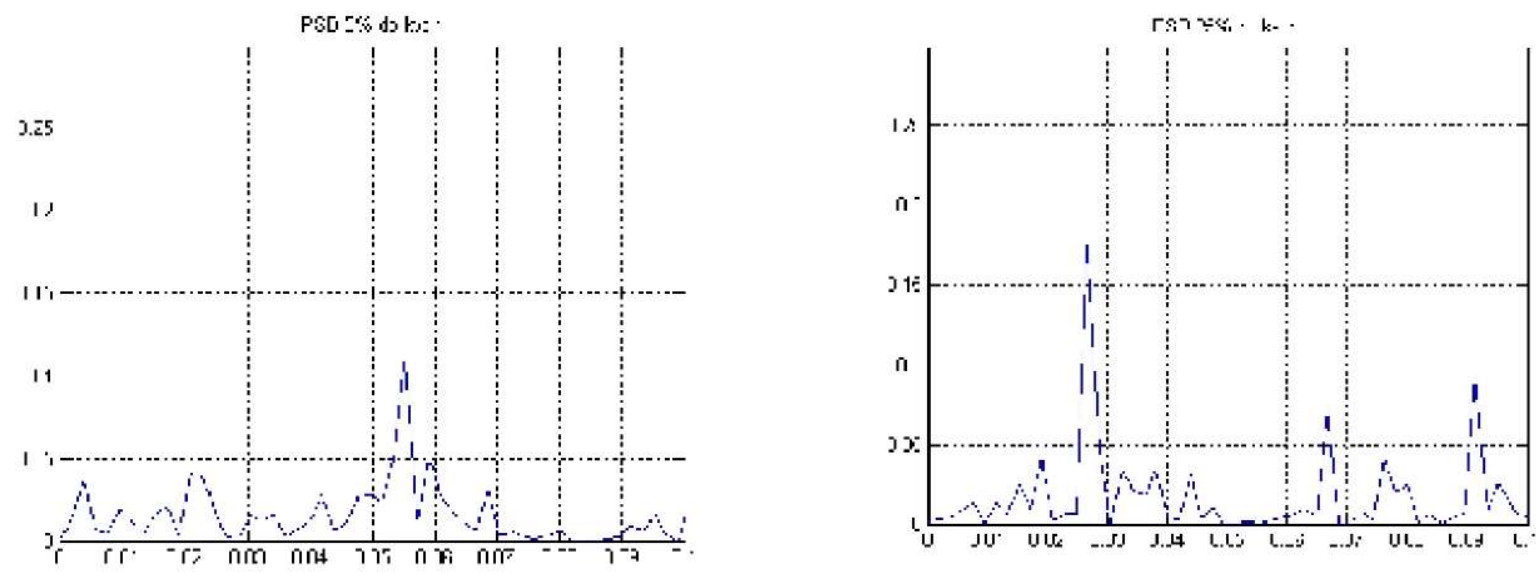

a
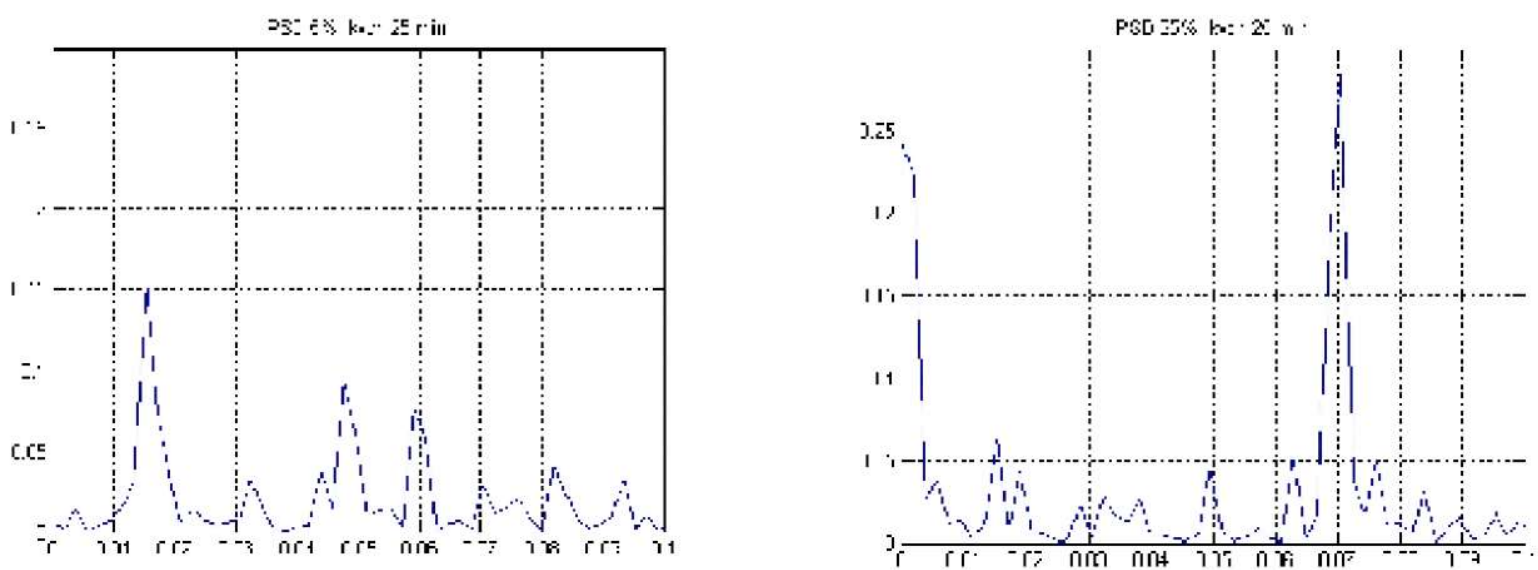

6
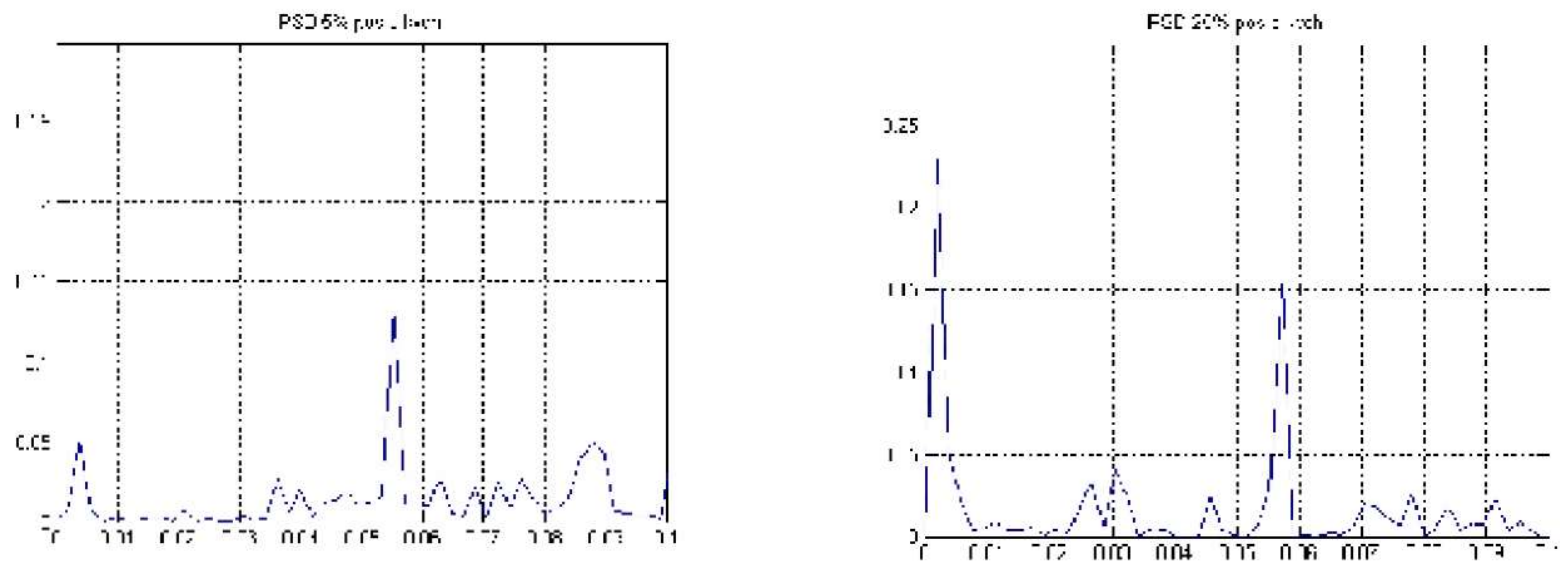

Puc. 3. Коефіцієнти Фур'є перетворення розчинів глюкози різних концентрацій: а) до впливу ВВЧ-випромінювання; б) під час впливу ВВЧ-випромінювання; в) після впливу ВВЧ-випромінювання.

На рисунку 4 показана дана залежність, а саме, лінійна прямо пропорційна залежність відносних величин повторення періодів автокореляційної функції від концентрації водного розчину глюкози. Ще більш виразна залежність відносних частот піків коефіцієнтів Фур' є перетворення від концентрації розчину показана на рисунку 5. Відносні частоти обернено пропорційні концентрації водного розчину глюкози. 


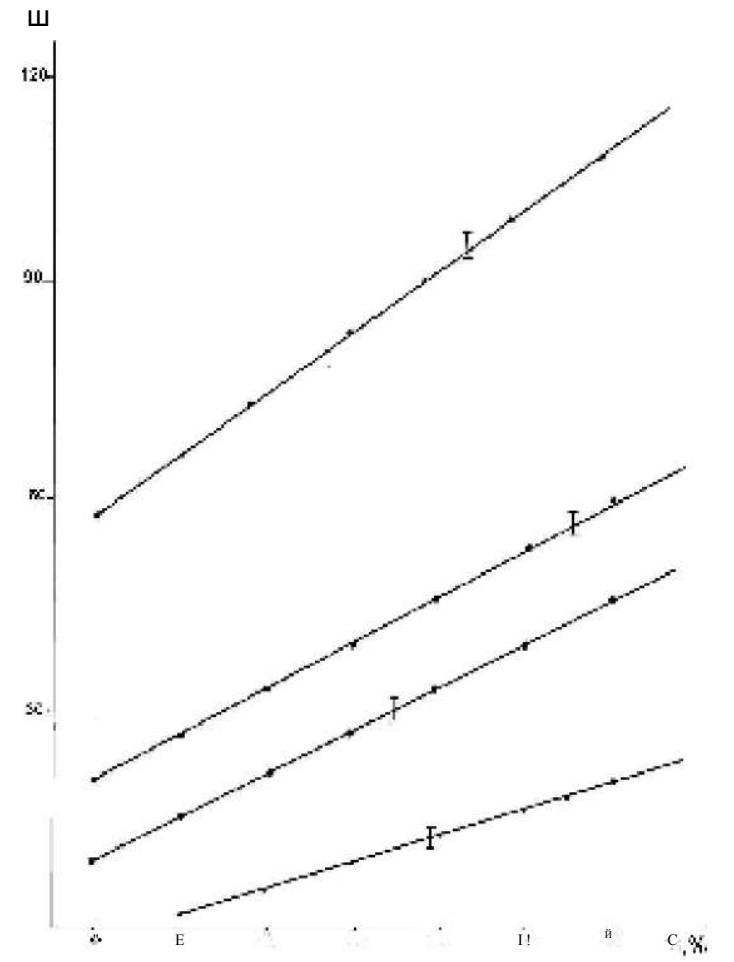

Puc. 4. Залежність відносних зсувів автокореляційної функції від концентрації водних розчинів глюкози.

Висновки. 1. Лінійна залежність відносних середніх величин випадкового процесу флуктуації диференціальної температури від концентрації водного розчину глюкози може бути використана в якості еталона для визначення та контролю розчинів 3 невідомою концентрацією при заданій температурі.

\section{Література}

1. Грилихес М. С. Контактная кондукгометрия: Теория и практика / М. С. Грилихес, Б. К. Филановский ; под ред. И. А. Агуфа.- Л. : Химия, 1980.- С. 175.

2. Иоффе Б. А. Рефрактометрические методы в химии : изд. 2-е / Б. А. Иоффе. - Л. : Химия, 1974. - С. 400.

3. Основы жидкостной хроматографии / [пер. с англ. ; под ред. А. А. Жуховицкого]. - М. : Мир, 1973. - С. 264.

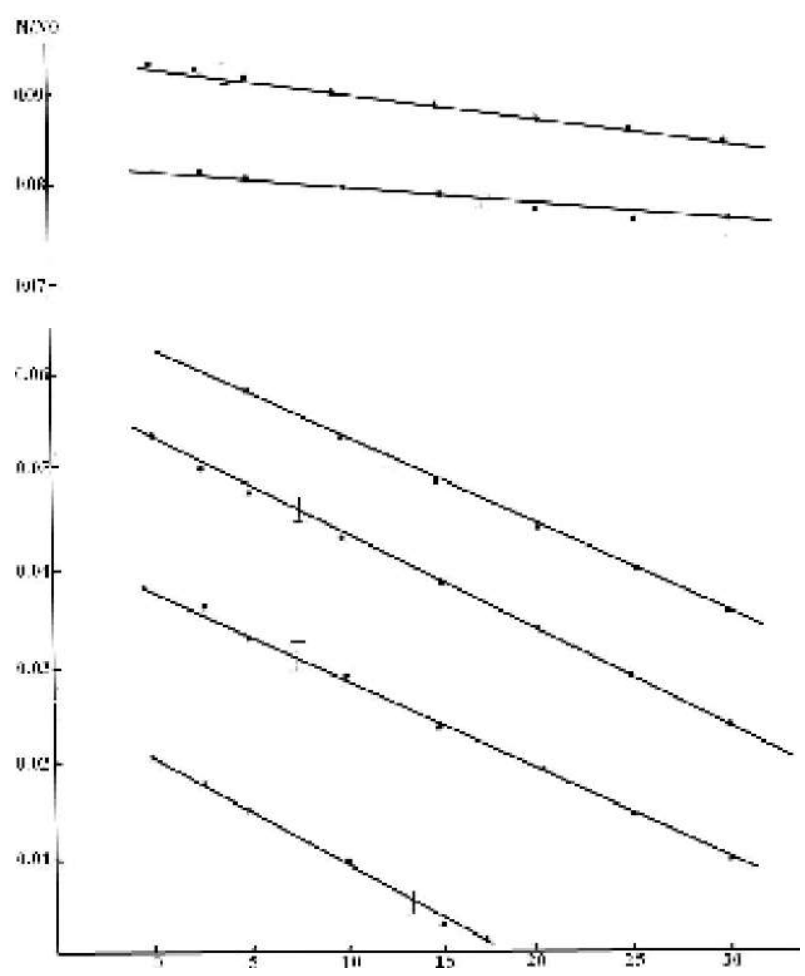

Puc. 5. Залежність відносних значень піків коефіцієнтів перетворення Фур'є від концентрації водних розчинів глюкози.

2. Представлена методика вважається перспективною для неінвазивної діагностики біологічних розчинів організму, оскільки вимірювання флуктуацій температури проводиться у проміжному середовищі між організмом і вимірювальним комплексом.

4. Фишер И. 3. Статистическая теория жидкостей : 2 экз. / И. 3. Фишер. - М. : Физматдиз, 1961. - С. 280.

5. Лошицький П. П. Дослідження змін властивостей води і водних розчинів хлориду натрію при дії ВВЧ-випромінювання нетеплової інтенсивності / П. П. Лошицький, В. М. Мамаєв // Медична інформатика та інженерія. - 2008. - №> 1. - C. 53-60. 